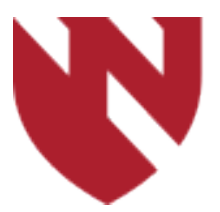

\title{
Effect of 75\% Intestinal Resection on Body Composition in Lean vs. Obese Rats
}

\author{
Ujwal R. Yanala \\ University of Nebraska Medical Center \\ Roger Reidelberger \\ University of Nebraska Medical Center \\ Jon Thompson \\ University of Nebraska Medical Center \\ Mark Carlson \\ University of Nebraska Medical Center
}

Tell us how you used this information in this short survey.

Follow this and additional works at: https://digitalcommons.unmc.edu/gmerj

Part of the Higher Education Commons, and the Medicine and Health Sciences Commons

\section{Recommended Citation}

Yanala, U. R., Reidelberger, R., Thompson, J., , Carlson, M. Effect of 75\% Intestinal Resection on Body Composition in Lean vs. Obese Rats. Graduate Medical Education Research Journal. 2019 Dec 13; 1(1). https://digitalcommons.unmc.edu/gmerj/vol1/iss1/75

This Conference Proceeding is brought to you for free and open access by DigitalCommons@UNMC. It has been accepted for inclusion in Graduate Medical Education Research Journal by an authorized editor of DigitalCommons@UNMC. For more information, please contact digitalcommons@unmc.edu. 
Effect of $75 \%$ Intestinal Resection on Body Composition in Lean vs. Obese Rats

Creative Commons License

(ब) $(1) \Theta$

This work is licensed under a Creative Commons Attribution-Noncommercial-No Derivative Works 4.0 License. 


\section{Effect of Proximal Versus Distal 50\% Enterectomy on Nutritional Parameters in Rats Preconditioned with a High-Fat Diet or Regular Chow \\ Ujwal Yanala, Roger Reidelberger, Jon Thompson, Valerie Shostrom, Mark Carlson}

Mentor: Mark Carlson

Program: General Surgery

Introduction: The purpose of this study was to determine whether obese vs. non-obese rats would respond differently after $50 \%$ enterectomy. We hypothesized that nutritional parameters would be less adversely affected by massive resection obese rats relative to non-obese rats.

Methods: Rats (CD®IGS; male; 5 months, N $=75$ ) were fed ad libitum with either a high fat diet (obese rats) or normal rat chow (lean rats) during a four month induction period, and then were randomized into one of three surgical procedures: (1) resection of the proximal half of small bowel; (2) resection of the distal half of small bowel; (3) small bowel transection with re-anastomosis (control/sham resection). Food intake, weight, and body composition were monitored before and for 4 weeks after surgery. Data analyzed with twoway ANOVA and t-tests;

Results: Obese rats lost less lean mass in the postoperative period compared to lean rats. In lean but not obese rats, $50 \%$ distal resection appeared to produce a greater decrease in body weight, percent body weight, and percent body fat when compared to control surgery. Fasting levels of leptin, insulin, and GIP were higher in obese compared to lean rats at time of sacrifice. Ghrelin appeared to increase in subjects having a $50 \%$ distal resection.

Conclusions: The high fat diet induced obesity without a change in lean mass during the four month induction period. All subjects appeared to lose weight after surgery, with distal resection appearing to produce greater weight and fat loss in lean rats. The presence of obesity seemed to be protective of lean body mass after any surgery, and also appeared to be protective of fat mass after a $50 \%$ distal resection. Whether the increased levels of leptin, insulin, and GIP in obese subjects contributed to these protective effects is speculative.

https://doi.org/10.32873/unmc.dc.gmerj.1.1.074

\section{Effect of $75 \%$ Intestinal Resection on Body Composition in Lean vs. Obese Rats Ujwal Yanala, Roger Reidelberger, Jon Thompson, Mark Carlson}

Mentor: Mark Carlson

Program: General Surgery

Purpose: Clinical data have suggested that obese patients tolerate Short Bowel Syndrome (SBS) better than non-obese patients. We hypothesized that in rats, pre-existing obesity would promote conservation of lean mass after a $75 \%$ distal small intestinal resection.

Methods: Rats $(\mathrm{CD} \cap \mathrm{IGS}$; male; age $=2$ months at study initiation) were fed ad-lib with either a high-fat diet (HF, $45 \% \mathrm{kcal}=$ fat $/ 17 \% \mathrm{kcal}=$ sucrose $)$ or low-fat $\operatorname{diet}(\mathrm{LF}, 10 \% \mathrm{kcal}=\mathrm{fat} / 0 \% \mathrm{kcal}=$ sucrose $)$ during a five month induction period, and then were stratified into either $75 \%$ distal small intestinal resection or small bowel transection/re-anastomosis (sham resection). All rats were fed an intermediate diet ( $25 \% \mathrm{kcal}=$ fat $/ 17 \% \mathrm{kcal}=$ sucrose $)$ during the two-month post-resection observation. Body weight and composition (quantitative mass resonance) data were accumulated throughout the study.

Results: Just prior to resection, the \%body fat in LF vs. HF subjects was $25.2 \pm 4.7$ (range 16.1-34.8) vs. $35.7 \pm 4.1$ (range 24.5-43.0), respectively ( $\mathrm{p} \leq 0.0001$, Kruskal-Wallis). The post-resection (two month) change in lean mass ( $\Delta$ Lean) was negligible in the sham-resected subjects (Table 1), but was negative in the resected subjects. There was no statistical difference in $\Delta$ Lean between resected LF vs. HF subjects. Resection decreased both body weight and fat compared to sham-resection, but changes $(\Delta \mathrm{Wt}$ and $\Delta$ Fat) were greater in resected HF compared to LF subjects.

Conclusion: The HF diet induced obesity ( $>30 \%$ body fat). The $75 \%$ distal resection decreased body weight, fat, and lean mass in subjects on both diets. Subjects on the HF diet did not retain lean mass after resection better than the LF subjects. In this model of SBS, pre-existing obesity did not appear to be protective of lean mass.

https://doi.org/10.32873/unmc.dc.gmerj.1.1.075

\section{II- $\beta$ (Interleukin- $\beta$ ) and Tnf- $\alpha$ (Tumor Necrosis Factor- $\alpha$ ) Impact Abdominal Aortic Aneurysm Formation by Differential Effects on Macrophage Polarization}

Rishi Batra, Melissa Suh, Jeff Carson, Matt Dale, Trevor Meisinger, Matt Fitzgerald, Jiangtao Luo, Irkalis Pipinos, Wanfen Xiong, Timothy Baxter

Mentor: Tim Baxter

Program: General Surgery

Introduction: Abdominal aortic aneurysms (AAAs) are inflammatory in nature and are closely associated with smoking. Our purpose was to identify differential cytokine expression by circulating $\mathrm{T}$ cells from AAA patients and controls (atherosclerosis, no AAA). Based on this analysis, we further explored the mechanism of action of interleukin (IL)-1b.

Methods: Activated T cells from AAA patients and matched atherosclerotic controls with normal aortic diameter were studied for differential cytokine expression. Levels of IL$1 \mathrm{~b}$ were measured in human plasma.
We explored the mechanism of action of IL-1b using a murine model of AAA and cell culture. The effects of IL-1b deletion on M1 macrophage polarization were compared to another pro-inflammatory cytokine, tumor necrosis factor (TNF)-a. Bone marrowderived macrophages from IL-1b-/- and TNF-a-/- mice were polarized to an M1 phenotype and infused into mice.

Results: IL-1b was differentially expressed by activated $\mathrm{T}$ cells and in human plasma, with lower levels detected in AAA patients compared to matched controls (Figure). Genetic deletion of IL-1b and IL-1R-/- did not inhibit aneurysm formation or decrease MMP expression. TNF-a deletion, but not IL-1b deletion, inhibited M1 macrophage polarization. Infusion of M1 polarized TNF-a/- macrophages inhibited aortic diameter growth, no inhibitory effect was seen in mice infused with M1 polarized IL-1b-/macrophages.

Conclusions: Our studies suggest that IL-1b inhibits outward remodeling in the aorta. While IL-1b is a pro-inflammatory cytokine, its effects on macrophage polarization differ from TNF-a. The differential effects of TNF-a and IL- $1 \mathrm{~b}$ inhibition on M1 macrophage polarization may account for the differences in clinical efficacy of TNF-a and IL-1b antibody therapies in management of inflammatory diseases.

https://doi.org/10.32873/unmc.dc.gmerj.1.1.076 